\title{
Figures and tables
}

Figures

1.1 England and Wales: diphtheria deaths, 1931-48

3.1 Poliomyelitis notifications, 1939-69

4.1 Pertussis notifications, England and Wales, 1940-2005

5.1 Percentage of children receiving first dose of MMR before 24 months in London, rest of England and Scotland, 1999-2000, 2015-16

5.2 Mentions of MMR in major daily newspapers, 1996-2016

5.3 Notifications of measles in England and Wales, 1940-2015

\section{Tables}

1.1 Family background and immunisation

1.2 Diphtheria notifications and deaths in England and Wales, 1938-60

2.1 Importations of smallpox into England and Wales, 1936-70

2.2 Select vaccination rates as at 31 December 1964 